\title{
Spatial Distribution and Associated Factors of Neonatal Mortality in Ethiopia: using Ethiopian Demographic and Health Survey 2016
}

\section{Gedamnesh Bitew Deres}

University of Gondar College of Medicine and Health Sciences

\section{Destaw Fetene Teshome}

University of Gondar College of Medicine and Health Sciences

Ayenew Molla Lakew ( $\square$ mayenew15@gmail.com )

Institute of Public Health, College of Medicine and Health sciences, University of Gondar, Ethiopia https://orcid.org/0000-0003-3648-9891

Research article

Keywords: EDHS, Neonatal mortality, spatial distribution, associated factors, Ethiopia

Posted Date: March 2nd, 2020

DOI: https://doi.org/10.21203/rs.3.rs-15617/v1

License: (c) (i) This work is licensed under a Creative Commons Attribution 4.0 International License. Read Full License 


\section{Abstract}

Background: Neonatal mortality is continuing on top of the agenda of public health and international development agencies. In Ethiopia, it is still high accounts $60 \%$ infant mortality and $43 \%$ of under-five mortality. However, the distribution of the problem across the regions of Ethiopia is not well addressed. Therefore, this analysis aimed to assess spatial distribution of neonatal mortality and identify associated factors in Ethiopia using the 2016 Ethiopian Demographic Health Survey (EDHS). Exploring spatial distribution and identifying associated factors is important to select priority areas and design effective intervention program to reduce neonatal mortality.

Methods: The analysis included 7,193 live births, selected by stratified two-stage cluster sampling techniques. Spatial analysis was done to explore spatial distribution of neonatal death using Geographic information system and Sat scan. Multilevel logistic regression was fitted to identify individual and community level factors associate with neonatal mortality.

Results: The hot-spot areas for neonatal mortality were Amhara, West Tigray, northeast, southwest and central part of Oromia. Mother's with age $>35$ years ( $A O R=2.25,95 \mathrm{Cl} \%: 1.47,3.45)$, family size of $3-5$ $(A O R=0.14,95 \mathrm{Cl} \%: 0.06,0.36)$ and 6 and above $(A O R=0.08,95 \% \mathrm{Cl}: 0.02,0.20)$, male neonates $(A O R=3.45$, $95 \% \mathrm{Cl}: 2.27,5.22)$, smaller birth size ( $\mathrm{AOR}=1.61,95 \% \mathrm{Cl}: 1.02,2.54)$, birth interval less than 2 years $(A O R=3.58,95 \% \mathrm{Cl}: 1.66,7.70)$ and 2 years and more (AOR=2.54, 95\%Cl: $1.26-5.11)$, early initiation of breast feeding ( $A O R=0.20,95 \% \mathrm{Cl}: 0.09-0.42)$, had no $A N C$ visit $(A O R=1.68,95 \% \mathrm{Cl}: 1.08,2.60)$, did not receive PNC services (AOR=3.58, 95\%Cl: $1.13-11.33$ ) and $\mathrm{C} / \mathrm{S}$ delivery $(\mathrm{AOR}=19.55,95 \% \mathrm{Cl}$ : 8.07, 47.34) were statistically significant variables for neonatal mortality.

Conclusions: High risk areas for neonatal mortality were identified in northern, central and southwest part of the Ethiopia. Individual level variables were important factors associated with neonatal mortality. Focusing on maternal health care services, increase birth interval and initiation of breast feeding early will be needed to reduce neonatal mortality.

\section{Background}

Neonatal mortality is the death of new born up to first 28 days after birth (1). Globally, 2.5 million deaths occurred in the first month of life at rate of 18 deaths per 1,000 live births which accounts $47 \%$ of underfive mortality in 2017. The majority, $80 \%$ of neonatal deaths, occurred in Sub-Saharan Africa (27 per 1000 live births) and South Asia countries (2). In spite of many efforts taken by Ethiopian government and other stakeholders, neonatal death is still high, 29 per 1000 live births, which accounts $60 \%$ of infant mortality and $43 \%$ of under-five mortality. The reduction progress was by $41 \%$ from 49 to 29 per 1000 live births for the last 16 years from 2000 to 2016 (3).

Neonatal mortality is continuing on top of the agenda of public health and international development agencies because sustainable development goals (SDGs) for child survival cannot be met without substantial reductions in neonatal mortality. Reduction of neonatal death would be important to achieve 
both the neonatal and under-five mortality targets of the sustainable development goals. The SDGs have two specific targets to reduce the neonatal mortality rate and under-five mortality rate to 12 and 25 per 1000 live-births within 2030 (4).

The majority of neonatal deaths are caused by preventable or treatable diseases worldwide like neonatal sepsis or pneumonia, tetanus, birth asphyxia, low birth weight, preterm birth complications, congenital abnormalities and other causes $(2,5)$. Previous studies showed that leading causes of new born death are prematurity, low birth weight, asphyxia, infections, congenital abnormalities and other causes $(6,7)$. Many literatures also indicated that neonatal mortality was influenced by mother's age, educational status of mother and father, income condition, residence, regional differences, neonatal related factors, maternal health care services and obstetric related factors (8-10).

Although there are studies conducted on neonatal mortality and associated factors in Ethiopia, they did not show the spatial distribution of the problem in the country. Neonatal mortality varies in the country in space and time by changing its magnitude. The individual and community level factors were also not addressed previously.

The present study therefore, aimed to examine the spatial patterns and identify determinants of neonatal mortality in Ethiopia using the 2016 EDHS data. First, the study examined whether there was a significant global spatial autocorrelation for the neonatal mortality. If the presence of global spatial dependency was confirmed, local spatial autocorrelation was explored, and map the spatial distribution of neonatal mortality by region.

The spatial exploration of neonatal mortality would have an important implications to select priority areas design targeting policy for effective intervention program to reduce neonatal mortality

\section{Methods}

\section{Study setting and period}

The data for this study were collected in all nine regions and two city administrations of Ethiopia from January 18 to June 27, 2016. Each region is subdivided into zones, and zones into administrative units called district. Each district is further subdivided into the lowest administrative unit, called kebeles. There are a total of 68 zones, 817 districts and 16,253 kebeles in the country (3).

\section{Population and Sample}

All neonates in Ethiopia born within the five years preceding the survey were the source population, whereas all neonates in Ethiopia who were in the selected clusters were considered as the study population. Neonates with incomplete data, and longitude and latitude zero degree for spatial data exploration were excluded from the analysis. 
A total of 7,193 live births taken from 645 (202 in urban and 443 in rural areas) Enumeration Areas (EA) were included in the analysis. Stratified two-stage cluster sampling was used to select the estimated sample. Each region was stratified into urban and rural areas, yielding 21 sampling strata. Samples of EAs were selected independently in each stratum in two stages. In the first stage 645 clusters of EAs were selected, 18,008 households were enumerated in the second stage (3). The 7,193 household had neonates during the data collection and all neonates were included in the analysis.

\section{Data collection Procedures}

The source of this study was the 2016 EDHS. Permission letter for the use of this data were obtained, and data sets were downloaded from the Measure Demographic web site: www.measuredhs.com.

Data for the original work were collected by using compressive standard questionnaires. The household Questionnaire, the woman's questionnaire and the man's questionnaire were used to collect socioeconomic and demographic information, women's birth history and other important information. After all questionnaires were finalized in English, they were translated into Amharic, Tigrigna, and Oromiffa. The collected data was back translated into English to keep consistence.

\section{Study variables}

Neonatal mortality was the dependent variable of the study. The independent variables were community level variables (region and residence) and Individual level variables. Individual level variables: demographic and socio-economic variable (mother's age, mother's education level, father's education level, wealth index, father's employment status, mother's employment status, marital status, family size, improved water source, improved toilets), Neonatal related variables( sex, birth interval, birth size and initiation of breast feeding) and maternal health service (ANC visit, PNC visit, Place of delivery, mode of delivery, multiple births, number of tetanus toxoid vaccine ).

\section{Data quality control}

The quality of this data was maintained by checking its completeness, cleaning the missing values by running frequency tables. In addition to this, the quality of original data were maintained by pretest the questionnaires in all three local languages (Amarigna, Oromiffa and Tigrigna), giving training for interviewers and interviewers used tablet computers to record response.

\section{Statistical Analysis}

Data were weighted to account different sampling probabilities and response rates. Descriptive measures were used to summarize the characteristics of the study participants using weighted frequencies and percentages for community level and individual level variables. Neonatal mortality rate across the regions was also estimated and displayed with the graph. 
Spatial autocorrelation was examined through global Moran's which is an indicator for spatial autocorrelation and measures whether spatial pattern of neonatal mortality was clustered, dispersed or random. The Moran's I value ranges from -1 to +1 . If the test statistics is significance $(P<0.05)$ and Moran's I value approaches -1 indicates dispersion and +1 indicates clustered, while if the test statistics is not significance, the observed pattern of neonatal mortality displays is random.

A Local Moran's I cluster map was used to determine local clustering of the neonatal mortality. It also measures whether there were positively correlated (high-high and low-low) clusters or negatively correlated clusters (high-low and low-high). Moreover, clusters high values (High-High) and clusters of low values (low -low) were identified. The level of clustering of the neonatal mortality within the area were identified using Z-score. High and low level of clustering of neonatal mortality was indicated a positive and negative Z-scores respectively.

High prevalence/low prevalence areas of neonatal mortality were determined using the Getis-Ord Gi. Hotspot and cold-spot areas identified and indicated by $\mathrm{Gi}^{*}$. The high-risk and low-risk regions for neonatal mortality was predicted by using Spatial kriging interpolation analysis.

Spatial sat scan analysis was conducted using SatScan software version 9.6 to investigate significant primary and secondary clusters of high neonatal mortality. The numbers of cases in each location have Bernoulli distribution and the model requires data cases and control. The default maximum spatial cluster size of $<50 \%$ of the population was used, as an upper limit, which allowed both small and large clusters to be detected and ignored clusters that contained more than the maximum limit. For each potential cluster, a likelihood ratio test statistic was used to determine if the number of observed mortality within the potential cluster is significantly higher than expected or not. The primary and secondary clusters are identified and reported with log likelihood ratio, relative risk and P-value.

\section{Model Building}

Multilevel logistic regression model was fitted to account for the clustering structure of the EDHS data. It was fitted to examine both individual and community level factors that associate with neonatal mortality. Variables having P-value up to 0.2 in the bi-variable analysis were selected to fit the multi-variable multilevel model. Finally, multilevel logistic regression analysis was performed to estimate the adjusted odds ratios and those variables with P-value of $<=0.05$ was considered as statistically significant.

Four multilevel analysis models were fitted using STATA 14. Model I (null model) was fitted without explanatory variables to test random variability in the intercept and intra-class correlation coefficient (ICC) was determined. Model II was fitted to explore the effect of community level variables, Model III was fitted to examine the effect of individual level variables and Model IV was fitted to indicate the effects of both individual and community level characteristics simultaneously.

The effects of individual-level and community-level factors on neonatal mortality were reported in term of odds ratios with $95 \%$ confidence interval. Random effects were expressed in terms of Intra-Cluster 
Correlation (ICC) and proportional change Variance (PCV).

The log likelihood and Akaikie Information Criterion (AIC) of the models were estimated to assess the fitness of the model relative to the other models. Variance Inflation Factor were used to identify the presence of multi-collinearity in the model.

\section{Results}

\section{Community level characteristics}

A total weighted 7,590 live births within five years preceding the EDHS 2016 were included in the analysis. About $6,621(87.23 \%)$ of the study participants were from rural and $3,130(41.23 \%)$ of the neonates were from Oromia (Table 1).

\section{Individual level characteristics}

\section{Socioeconomic and Demographic characteristics}

About 2,165 (28.53\%) neonates were born from mothers aged 25-29 years. The mean age of the mothers was 29.25 ( $\pm 6.8 \mathrm{SD}$ ) years. Of the mothers, $4,791(63.12 \%)$ of them have no formal education and 7,165 $(94.4 \%)$ were married (Table 2$)$.

\section{Neonatal related characteristics}

Of the neonates, $3,941(51.92 \%)$ were males and 3,081(40.59\%) had average birth size according to their mother's perception. About 6,378(84.09) neonates were initiated breast milk within one hour of birth.

\section{Maternal health care services and obstetric characteristics}

Among mothers 4,757(62.67\%) had antenatal care visits during their last pregnancy, and 2,524 (33.25\%) of the mothers were delivered at health facilities. Only $636(8.36 \%)$ of the neonates had postnatal care checkup (Table 3).

\section{Regional neonatal mortality rate}

The NMR varies across the regions of the country. The highest and the lowest NMR were observed in Oromia (25 per 1000 life birth) and Adis Abeba (7.5 per 1000 life birth) respectively (Figure 1).

\section{Spatial Analysis of Geographic Information System}

The spatial autocorrelation analysis indicated that the spatial distribution of neonatal mortality was nonrandom. The Global Moran's Index was 0.19 (P-value <0.001) indicates that there was significant clustering of neonatal mortality (Figure 2). 
Hot spot (high risk) regions for neonatal mortality were observed in Amhara, west Tigray, northeast, southwest and central part of Oromia. However, Afar, Benshangul-Gumz, Gambela, DireDawa, Harari and, northeast part of Southern Nations, Nationalities and Peoples (SNNP) were identified as cold spot (low risk) regions for neonatal mortality in Ethiopia (Figure 3).

The analysis of cluster and outliers indicated that high outlier clusters and low outlier clusters had nearly equal occurrence. These high outliers were observed on Oromia, border of SNNP and Oromia, border of Benshagul-Gumiz and Oromia, border of Benshagul-Gumiz and Amhara regions. However, low outliers were found in Tigray, Amhara, Oromia, South Afar and SNNP (Figure 4).

The spatial kriging interpolation analysis was used to predicted high risk regions for neonatal mortality. Predication of high risk areas were indicated by red predictions. Southeast and northwest part of Amhara, central and northeast Oromia, Adis Abeba, Tigray and north SNNP were predicted as more risky areas compared to other regions. Whereas, Afar, Benshagul-Gumiz, west Oromia, Somali, SNNP and Gambela were predicated as having less risk for neonatal mortality (Figure 5).

\section{Spatial sat scan analysis}

Nine most likely (primary) clusters were identified and all of them were significant. The primary clusters spatial window was located in central Oromia. It was centered at $7.634301 \mathrm{~N}, 39.484474 \mathrm{E}$ with $80.38 \mathrm{~km}$ radius, with RR of 4.61 and LLR of 21.05, at P-value $<0.001$. The RR of 4.61 for clusters of spatial window means neonates within the spatial window had 4.61 times higher risk for death than neonates outside the window. In addition to this, 52 significant secondary clusters were located in BenshagulGumiz, west Amhara and western Oromia. It was centered at 11.340042 N, 35.12673 E with 212.45 km radius, with $\mathrm{RR}$ of 3.69 and LLR of 11.65 , at $\mathrm{P}$-value $=0.003$. The RR of 3.69 for clusters spatial window means neonates within the spatial window had 3.69 times higher risk for death than neonates outside the window (Figure 6).

\section{Multilevel logistic regression analysis}

The value ICC for Null model was 0.38 which indicates $38 \%$ of the total variance in neonatal mortality in Ethiopia can be attributed to the communities in which the mothers were residing Four multi-level models (null model, model fitted with community level variables, model fitted with individual level variables and model fitted with community and individual level variables) were fitted in this study. Then, models were compared by their log likelihood and AIC. Model fitted with community and individual level variables had highest log likeli hood and lowest AIC. This model was selected for analysis.

The fixed effects (measure of association) and the random intercepts for the use of neonatal mortality are presented in Table 4. In the multi-variable multilevel logistic regression mother's age, family size, smaller than average birth size, birth interval, sex of the neonate, breastfeeding initiation time, ANC visit, PNC visit and mode of delivery were statically significant variables for neonatal mortality. 


\section{Discussion}

The aim of this study was to assess spatial distribution and associated factors of neonatal mortality in Ethiopia using 2016 EDHS data. The spatial analysis indicated that high risk regions for neonatal mortality were observed in northern (Amhara, west Tigray), southwest and central (northeast, southwest and central part of Oromia). In contrast, Afar, Benshangul-Gumz, Gambela, Dire Dawa, Harari and northeast part of SNNP were identified as low risk regions for neonatal mortality. The Sat scan statistical analysis showed that primary clusters were located in central Oromia and secondary clusters were existed in Benshagul-Gumiz, west Amhara and western Oromia. The probable explanation for geographic variation in the risk of neonatal mortality is the distribution of causes of neonatal mortality in the country. A common cause of neonatal mortality in Ethiopia is low birth weight, preterm birth, neonatal sepsis, congenital and other causes. A systematic review and meta-analysis done in Ethiopia on prevalence of low birth weight and associated factor indicated that high prevalence of low birth weight existed in the Tigray, Amhara and Oromia region(11). In addition to this, these regions had high prevalence of preterm birth $(12,13)$ and neonatal sepsis $(14)$.

The odds of neonatal death among neonates born from mothers' age 35-49 was 2.25 times more than that of neonates born from mothers' age 20-34 years. This finding is consistent with studies done in Ethiopia $(15,16)$ and Sudan $(17)$. The possible explanation could be due to older mothers have increased risk of over birth weight, gestational diabetes mellitus, gestational hypertension, postpartum hemorrhage which are risk factors for bad birth outcome (18-20).

This study revealed that neonates born from mothers with $3-5$, and 6 and above family members were $86 \%$ and $92 \%$ less likely to have neonatal mortality as compared with neonates born from mothers with 1-2 family size respectively. The result supported by the study done in West Gojam (10). The possible reasons might be due most mothers having large family members assumed to be multi-parity. These multi-parity mothers had low risk of low birth weight, pregnancy and delivery complications that decreases neonatal death (21).

The sex of the new born significantly influenced the occurrence of neonatal mortality.

This study indicated that male neonates were 3.45 times more likely to die within neonatal period than female neonates. This finding is similar studies done in Butajira (22), Zambia (23), Pakistan (24) and India (25). The possible justification might be due to male neonates have increased risk for congenital malformation $(26,27)$ and more susceptible to infections disease due to immune deficiencies $(28)$.

Neonates born with preceding birth interval of less than 2 years and 2 years and more were 3.58 times and 2.33 times more likely to die within neonatal period as compared with neonates born in first order respectively. This finding is in line with previous studies done in West Gojam (10), Ethiopia (29),Nigeria (30) and Bangladesh (31). The possible reason might be due to mother who have short birth interval increased the risk of maternal nutritional depletion, folic acid depletion, transmission of infection and sibling competition for breastfeeding and parental resources leads to adverse neonatal outcome (32). 
The birth size of the neonates had associations with neonatal mortality. This study showed that the odds of neonatal death among neonates with birth size perceived by their mothers as smaller than average was 1.61 times more than neonates with birth size perceived by their mother as average. This finding is similar with studies done Ethiopia (33) and Afghanistan (34). The possible justification might be due to smaller than average birth size neonates indicate low birth weight babies and may result from premature births that increased the risk immune immaturity that predispose for infections, mental retardation, hypothermia and other complication (35).

Neonates initiated breast feeding early were lower the odds of neonatal death by $80 \%$ as compared to neonates initiated breast feeding lately. This finding is consistent with studies done in Felege Hiwot hospital (36) and India (37). The possible justification might be due to the first liquid come out from the breast that is called Colostrum is very important for the new-born babies to protect them from infections as it is rich in antibodies that leads to decrease neonatal mortality (38).

The odds of neonatal death among neonates born from mothers had no antenatal care visit was increased by $68 \%$ as compared to neonates born from mothers had antenatal care visit. The result is in line with studies conducted in Jimma (7), Gazi- strep (39) and India (37). This is because of attending ANC provide opportunity for screening danger signs of pregnancy complication and health workers give good information about safe delivery, delivery complication, breast feeding and neonatal care $(21,40)$.

Utilization of postnatal services was related with neonatal mortality. This study revealed neonates who did not received postnatal care were 3.58 times more likely to die within neonatal period than neonates who received postnatal care. This finding is supported by previous studies done in Ghana (9) and India (37). The possible justification might be due to receiving postnatal care services used to identify early danger signs, treat neonatal disease and prevent complication that improves neonatal health $(41,42)$.

The odds of neonatal death among neonates born by cesarean section were 19.55 times more than neonates born by normal. The result is consistent with studies conducted in Sudan (17) and Pakistan (43). This might be due most C/S deliveries done by emergency after labor complication and fetal distress that increased the risk of neonatal morbidity and mortality (44).

\section{Conclusions}

High risk areas for neonatal mortality were found in northern, central and southwest part of the country. In contrast, low risk areas were identified in western, northwest, eastern and northeast part of the country.

Community level variables were found to be less important factors to design strategies for reducing neonatal mortality. Individual level variables like being male, having smaller than average birth size, born from mothers did not attend ANC visit, had no postnatal care check-up, delivered by caesarean section and born from mothers age 35-49 years were factors that increase the risk of death in neonatal period. Whereas, having large birth interval, born from mothers with large family size and initiating breast feeding early were factors that decrease the risk of neonatal death. 
Federal ministry of health needs give priority for northern, central and southwest part of the country that has high risk for neonatal mortality and Improve maternal health care services coverage. Health professionals give emphasis to increase ANC for pregnant mothers and giving PNC for new born, advice mothers to increase birth interval and advice mothers to initiate breasts feeding within early. Researchers can use study as baseline to conduct a study for the reasons why northern, central and southwest part of the country have high neonatal mortality

\section{List Of Abbreviations}

AIC: Akaikie Information Criteria, ANC: Antenatal Care, C/S: Cesarean Section, DHS: Demographic Health Surveys, EA: Enumeration Area, EDHS: Ethiopian Demographic and Health Survey, GIS: Geographic Information System, ICC: Intra Class Correlation, LLR: Loglikelihood Ratio, NMR: Neonatal Mortality Rate, PNC: Postnatal Care, proportional change Variance (PCV), RR: Relative Risk, SDG: Sustainable Development Goals, SNNP: Southern Nations, Nationalities and Peoples, TT: Tetanus Toxoid.

\section{Declaration}

\section{Ethics approval}

Ethical clearance was obtained from the Ethical Review Board of Institute of Public Health, College of Medicine and Health Sciences, University of Gondar. Permission letter was gotten from Measure DHS International Program which authorized the data-sets. All the data used in this study are publicly available, aggregated secondary data with not having any personal identifying information that can be linked to particular individuals, communities, or study participants. Confidentiality of data was maintained anonymously in this study.

\section{Consent to publish}

Not applicable

\section{Competing interests}

The authors declare that they have no competing interests.

\section{Availability of data and materials}

All relevant information is within the manuscript. The data upon which the results based could be accessed on a reasonable request.

\section{Funding}

Funding was not secured for this study.

\section{Authors' contributions}


GBD conceived the study, performed data extraction and management carried out the statistical analysis and interpretation and wrote the draft manuscript. DFT and AML participated in the design of the study, revising design and analysis of the research, performed statistical analysis. All authors approved the final version of the manuscript.t

\section{Acknowledgments}

We would like to thank University of Gondar, College of Medicine and Health Sciences, Institute of Public Health, Department of Epidemiology and biostatistics to give this opportunity. And also, we would like to thank Measure Demographic Health Surveys authority.

\section{Authors' information}

GBDeres (MPH). D.F. (MPH, assistant professor) is a lecturer in the Department of Epidemiology and Biostatics, Institute of Public Health, College of Medicine and Health Sciences, University of Gondar, Ethiopia. A.M (MPH) is a lecturer in the Department of Epidemiology and Biostatics, Institute of Public Health, College of Medicine and Health Sciences.

\section{References}

1. Organization WH. Neonatal and perinatal mortality: country, regional and global estimates. 2006.

2. United Nations Inter agency Group for Child Mortality Estimation (UNIGME) .Levels \& Trends in Child Mortality.Estemates developed by United Nations Inter-agency Group for Child Mortality Estimation', United Nations Children's Fund, New York. 2018.

3. Central satastical Agency.Ethiopia Demograghic health survey 2016. Addis Ababa, Ethiopia ,and Rockville, Maryland, USA :CSA and ICF. 2016.

4. United Nations, Sustainable Development Goals. http://www.un.org/sustainabledevelopment/health/. Accessed feburary10. 2019.

5. Lawn JE, Cousens S, Zupan J, Team LNSS. 4 million neonatal deaths: when? Where? Why? The lancet. 2005;365(9462):891-900.

6. Mengesha HG, Sahle BW. Cause of neonatal deaths in Northern Ethiopia: a prospective cohort study. BMC public health. 2017;17(1):62.

7. Debelew GT, Afework MF, Yalew AW. Determinants and causes of neonatal mortality in Jimma zone, southwest Ethiopia: a multilevel analysis of prospective follow up study. PLoS One. 2014;9(9):e107184.

8. Hibstu DT, Ayele TA, Mengesha ZB. Determinants of Neonatal Mortality in Ethiopia: A Case Control Study, 2013. Open Access Library Journal. 2014;1(06):1.

9. Kayode GA, Ansah E, Agyepong IA, Amoakoh-Coleman M, Grobbee DE, Klipstein-Grobusch K. Individual and community determinants of neonatal mortality in Ghana: a multilevel analysis. BMC pregnancy and childbirth. 2014;14(1):165. 
10. Yirgu R, Molla M, Sibley L. Determinants of neonatal mortality in rural Northern Ethiopia: A population based nested case control study. PloS one. 2017;12(4):e0172875.

11. Endalamaw A, Engeda EH, Ekubagewargies DT, Belay GM, Tefera MA. Low birth weight and its associated factors in Ethiopia: a systematic review and meta-analysis. Italian journal of pediatrics. 2018;44(1):141.

12. Bekele I, Demeke T, Dugna K. Prevalence of preterm birth and its associated factors among mothers delivered in Jimma university specialized teaching and referral hospital, Jimma Zone, Oromia Regional State, South West Ethiopia. J Women's Health Care. 2017;6:356.

13. Teklay G, Teshale T, Tasew H, Mariye T, Berihu H, Zeru T. Risk factors of preterm birth among mothers who gave birth in public hospitals of central zone, Tigray, Ethiopia: unmatched case-control study 2017/2018. BMC research notes. 2018;11(1):571.

14. Mersha A, Worku T, Shibiru S, Bante A, Molla A, Seifu G, et al. Neonatal sepsis and associated factors among newborns in hospitals of Wolaita Sodo Town, Southern Ethiopia. Research and Reports in Neonatology. 2019;9:1.

15. Wakgari N, Wencheko E. Risk factors of neonatal mortality in Ethiopia. Ethiopian Journal of Health Development. 2013;27(3):192-9.

16. Yaya Y, Eide KT, Norheim OF, Lindtjørn B. Maternal and neonatal mortality in south-west Ethiopia: estimates and socio-economic inequality. PloS one. 2014;9(4):e96294.

17. Bashir AO, Ibrahim GH, Bashier IA, Adam I. Neonatal mortality in Sudan: analysis of the Sudan household survey, 2010. BMC Public Health. 2013;13(1):287.

18. Yogev Y, Melamed N, Bardin R, Tenenbaum-Gavish K, Ben-Shitrit G, Ben-Haroush A. Pregnancy outcome at extremely advanced maternal age. American journal of obstetrics and gynecology. 2010;203(6):558. e1-. e7.

19. Laopaiboon M, Lumbiganon P, Intarut N, Mori R, Ganchimeg T, Vogel J, et al. Advanced maternal age and pregnancy outcomes: a multicountry assessment. BJOG: An International Journal of Obstetrics \& Gynaecology. 2014;121:49-56.

20. Carolan M, Frankowska D. Advanced maternal age and adverse perinatal outcome: a review of the evidence. Midwifery. 2011;27(6):793-801.

21. Majoko F, Nyström L, Munjanja S, Mason E, Lindmark G. Relation of parity to pregnancy outcome in a rural community in Zimbabwe. 2004.

22. Gizaw M, Molla M, Mekonnen W. Trends and risk factors for neonatal mortality in Butajira District, South Central Ethiopia,(1987-2008): a prospective cohort study. BMC pregnancy and childbirth. 2014;14(1):64.

23. Chatupa M, Mwakazanga D, Mulenga D, Siziya S. Factors associated with neonatal deaths at Arthur Davidson Children's Hospital Ndola Zambia.

24. Nisar YB, Dibley MJ. Determinants of neonatal mortality in Pakistan: secondary analysis of Pakistan Demographic and Health Survey 2006-07. BMC Public Health. 2014;14(1):663. 
25. Singh A, Kumar A, Kumar A. Determinants of neonatal mortality in rural India, 2007-2008. PeerJ. 2013;1:e75.

26. Sokal R, Tata LJ, Fleming KM. Sex prevalence of major congenital anomalies in the United Kingdom: A national population-based study and international comparison meta-analysis. Birth Defects Research Part A: Clinical and Molecular Teratology. 2014;100(2):79-91.

27. Tennant PW, Samarasekera SD, Pless-Mulloli T, Rankin J. Sex differences in the prevalence of congenital anomalies: A population-based study. Birth Defects Research Part A: Clinical and Molecular Teratology. 2011;91(10):894-901.

28. Green MS. The male predominance in the incidence of infectious diseases in children: a postulated explanation for disparities in the literature. International Journal of Epidemiology. 1992;21(2):381-6.

29. Mekonnen Y, Tensou B, Telake DS, Degefie T, Bekele A. Neonatal mortality in Ethiopia: trends and determinants. BMC public health. 2013;13(1):483.

30. Akinyemi JO, Bamgboye EA, Ayeni 0 . Trends in neonatal mortality in Nigeria and effects of biodemographic and maternal characteristics. BMC pediatrics. 2015;15(1):36.

31. Kamal SM, Ashrafuzzaman M, Nasreen S. Risk factors of neonatal mortality in Bangladesh. Journal of Nepal Paediatric Society. 2012;32(1):37-46.

32. Conde-Agudelo A, Rosas-Bermudez A, Castaño F, Norton MH. Effects of birth spacing on maternal, perinatal, infant, and child health: a systematic review of causal mechanisms. Studies in family planning. 2012;43(2):93-114.

33. Kebede B, Gebeyehu A, Sharma HR, Yifru S. Prevalence and associated factors of neonatal mortality in North Gondar Zone, Northwest Ethiopia. Ethiopian Journal of Health Development. 2012;26(2):6671.

34. Al Kibria GM, Burrowes V, Choudhury A, Sharmeen A, Ghosh S, Mahmud A, et al. Determinants of early neonatal mortality in Afghanistan: an analysis of the Demographic and Health Survey 2015. Globalization and health. 2018;14(1):47.

35. Bernstein IM, Horbar JD, Badger GJ, Ohlsson A, Golan A, Network VO. Morbidity and mortality among very-low-birth-weight neonates with intrauterine growth restriction. American journal of obstetrics and gynecology. 2000;182(1):198-206.

36. Tewabe T, Mehariw Y, Negatie E, Yibeltal B. Neonatal mortality in the case of Felege Hiwot referral hospital, Bahir Dar, Amhara Regional State, North West Ethiopia 2016: a one year retrospective chart review. Italian journal of pediatrics. 2018;44(1):57.

37. Sari IP. The Determinants of Infant Mortality in Neonatal Period. Jurnal Kesehatan Masyarakat. 2016;12(1).

38. Edmond KM, Kirkwood BR, Amenga-Etego S, Owusu-Agyei S, Hurt LS. Effect of early infant feeding practices on infection-specific neonatal mortality: an investigation of the causal links with observational data from rural Ghana. The American journal of clinical nutrition. 2007;86(4):1126-31.

39. El Awour I, Abed Y, Ashour M. Determinants and risk factors of neonatal mortality in the Gaza Strip, occupied Palestinian territory: a case-control study. The Lancet. 2012;380:S25-S6. 
40. Vogel JP, Habib NA, Souza JP, Gülmezoglu AM, Dowswell T, Carroli G, et al. Antenatal care packages with reduced visits and perinatal mortality: a secondary analysis of the WHO Antenatal Care Trial. Reproductive health. 2013;10(1):19.

41. Gogia S, Sachdev HS. Home visits by community health workers to prevent neonatal deaths in developing countries: a systematic review. Bulletin of the World Health Organization. 2010;88:658-66.

42. Baqui AH, Ahmed S, El Arifeen S, Darmstadt GL, Rosecrans AM, Mannan I, et al. Effect of timing of first postnatal care home visit on neonatal mortality in Bangladesh: a observational cohort study. Bmj. 2009;339:b2826.

43. Jehan I, Harris H, Salat S, Zeb A, Mobeen N, Pasha O, et al. Neonatal mortality, risk factors and causes: a prospective population-based cohort study in urban Pakistan. Bulletin of the world Health Organization. 2009;87:130-8.

44. Sobhy S, Arroyo-Manzano D, Murugesu N, Karthikeyan G, Kumar V, Kaur I, et al. Maternal and perinatal mortality and complications associated with caesarean section in low-income and middleincome countries: a systematic review and meta-analysis. Lancet (London, England). 2019;393(10184):1973-82.

\section{Tables}

Table 1: Community level characteristics of study participants in Ethiopia, 2016

\begin{tabular}{llll}
\hline Variables & Categories & Weighted frequency(n) & Weighed percent (\%) \\
\hline Residence & Urban & 969 & 12.77 \\
& Rural & 6,621 & 87.23 \\
\cline { 2 - 4 } Region & Tigray & 537 & 8.01 \\
\cline { 2 - 4 } & Afar & 71 & 0.94 \\
\cline { 2 - 4 } & Amhara & 1,632 & 21.50 \\
\cline { 2 - 4 } & Oromia & 3,130 & 41.23 \\
\cline { 2 - 4 } & Somali & 269 & 3.57 \\
\cline { 2 - 4 } & Benshangul-Gumz & 81 & 1.06 \\
\cline { 2 - 4 } & SNNP & 1,601 & 21.09 \\
\cline { 2 - 4 } & Gambela & 21 & 0.27 \\
\cline { 2 - 4 } & Harari & 17 & 0.23 \\
\cline { 2 - 4 } & Addis Ababa & 198 & 2.61 \\
\cline { 2 - 4 } & Dire Dawa & 33 & 0.44 \\
\hline
\end{tabular}


Table 2: Socio-economic and demographic characteristics of the study participants in Ethiopia, 2016.

\begin{tabular}{|c|c|c|c|}
\hline Variables & Categories & $\begin{array}{l}\text { Weighted } \\
\text { frequency(n) }\end{array}$ & $\begin{array}{l}\text { Weighted percent } \\
\text { (\%) }\end{array}$ \\
\hline \multirow{7}{*}{ Mothers age } & $15-19$ & 339 & 4.47 \\
\hline & $20-24$ & 1,465 & 19.30 \\
\hline & $25-29$ & 2,165 & 28.53 \\
\hline & $30-34$ & 1,661 & 21.89 \\
\hline & $35-39$ & 1,206 & 15.89 \\
\hline & $40-44$ & 547 & 7.20 \\
\hline & $45-49$ & 207 & 2.73 \\
\hline \multirow{2}{*}{ Mothers employment } & Employed & 3,512 & 46.27 \\
\hline & Not employed & 4,078 & 53.73 \\
\hline \multirow{3}{*}{$\begin{array}{l}\text { Maternal } \\
\text { educational level }\end{array}$} & No education & 4,791 & 63.12 \\
\hline & Primary & 2,150 & 28.32 \\
\hline & Secondary\& above & 649 & 8.55 \\
\hline \multirow{5}{*}{ Wealth index } & Poorest & 1,269 & 16.72 \\
\hline & Poorer & 1,427 & 18.80 \\
\hline & Middle & 1,588 & 20.93 \\
\hline & Richer & 1,654 & 21.79 \\
\hline & Richest & 1,652 & 21.76 \\
\hline \multirow[t]{2}{*}{ Marital Status } & Currently married & 7,165 & 94.40 \\
\hline & $\begin{array}{ll}\text { Not } & \text { currently } \\
\text { married } & \end{array}$ & 425 & 5.60 \\
\hline \multirow{3}{*}{$\begin{array}{l}\text { Father's education } \\
\text { level }\end{array}$} & No education & 3,870 & 50.99 \\
\hline & Primary & 2,731 & 35.99 \\
\hline & Secondary \&above & 989 & 13.03 \\
\hline \multirow[t]{2}{*}{ Father's employment } & Employed & 6,581 & 86.71 \\
\hline & Not employed & 1,009 & 13.29 \\
\hline \multirow[t]{3}{*}{ Family size } & $1-3$ & 133 & 1.75 \\
\hline & $3-5$ & 3,503 & 46.16 \\
\hline & 6 and above & 3,594 & 52.09 \\
\hline
\end{tabular}

Table 3: Obstetric and maternal health characteristics of the study participants in Ethiopia, 2016 


\begin{tabular}{|c|c|c|c|}
\hline Variables & Categories & $\begin{array}{l}\text { Weighted } \\
\text { frequency(n) }\end{array}$ & $\begin{array}{l}\text { Weighted percent } \\
(\%)\end{array}$ \\
\hline \multirow[t]{2}{*}{ ANC visit } & No & 2,833 & 37.33 \\
\hline & Yes & 4,757 & 62.67 \\
\hline \multirow[t]{2}{*}{ Place of delivery } & $\begin{array}{l}\text { Health } \\
\text { facility }\end{array}$ & 2,524 & 33.25 \\
\hline & Home & 5,066 & 66.75 \\
\hline \multirow[t]{2}{*}{$\begin{array}{l}\text { Number of Tetanus Toxoid } \\
\text { vaccine }\end{array}$} & $\begin{array}{l}\text { None } \\
\text { one }\end{array}$ & 3,310 & 43.6 \\
\hline & $\begin{array}{l}\text { Two or } \\
\text { more }\end{array}$ & 4,280 & 56.4 \\
\hline \multirow[t]{2}{*}{ Postnatal care visit } & Yes & 636 & 8.38 \\
\hline & No & 6,954 & 91.62 \\
\hline \multirow[t]{2}{*}{ Mode of delivery } & Non C/S & 7,407 & 97.59 \\
\hline & $\mathrm{C} / \mathrm{S}$ & 183 & 2.41 \\
\hline \multirow[t]{2}{*}{ Multiple births } & No & 7,470 & 98.42 \\
\hline & Yes & 120 & 1.58 \\
\hline
\end{tabular}

Table 4: Multi-variable multilevel logistic regression analysis of individual and community level factors associated with neonatal mortality in Ethiopia, 2016 
Characteristics

Fixed effects

Residence

Urban

Rural

Region

Afar

Tigray

Amhara

Oromia

Somali

Benshagul-Gumiz

SNNP

Gambela

Harari

Adis Abeba

Dire Dewa

Mothers age

$$
\text { 20-34 }
$$

$15-20$

35-49

Family size

$$
1-2
$$

3-5

6 \&above

Father's educational level

No education

Primary

Secondary \&above

Marital status

Currently married

Not currently

married

Sex

Female

Male

Size of child at birth

Average
Model Model II

I
Model III

AOR (95\% CI)

AOR (95\%)

$\begin{array}{lc}1.00 & 1.00 \\ 1.78(0.67- & 2.12(0.73-6.17) \\ 3.48) & \end{array}$

1.00

$1.40(0.57-$

3.48)

$1.28(0.52-$

$3.14)$

$1.30(0.55-$

$3.04)$

3.06 (1.40-

6.69)

0.84 (0.32-

2.25)

$0.61(0.24-$

1.58)

$1.21(0.44-$

3.36)

1.78 (0.69-

4.59)

$0.77(0.15-$

3.80)

$1.40(0.43-$

4.60)
Model IV

AOR (95\% CI)

$2.12(0.73-6.17)$

1.00

1.68 (0.16-17.29)

$1.23(0.13-11.74)$

$1.16(0.12-10.87)$

$2.64(0.28-27.05)$

0.94 (0.05-19.53)

$0.56(0.06-5.61)$

$1.52(0.02-109.26)$

$1.25(0.22-72.71)$

$0.77(0.39-15.24)$

$1.62(0.04-60.61)$ 


\section{Birth interval}

Frist birth

$$
1.00
$$

Less than 2 years

\subsection{0}

Greater than 2years

Ante natal care

Yes

No

Postnatal care

2.55 (1.27-5.12)

3.58 (1.66-7.70)*

2.54 (1.26-5.11)*

Yes

1.00

No

$3.90(1.22-12.45)$

1.00

1.73(1.13-2.65)

1.68 (1.08-2.60)*

Number of Tetanus toxoid vaccine

Two or more TT None or one

Delivery mode

1.00

1.00

$1.23(0.80-1.88)$

1.00

16.09(6.91-37.45)

Cesarean

Breast feeding initiation time
Late

Early
1.00

$0.20(0.10-$

$0.44)$

\section{Random effects}

ICC (\%)

PCV (\%) $38 \%$

Model fitness

Log likelihood

AIC reference

$4 \%$

$5 \%$

$25 \%$

Model I Model II

$-712.00$

$-706.10$

$1428.016 \quad 1438.214$

Model III

$-624.67$

1301.332

Model IV

$-619.35$

1298.720

47.34)**

1.00

3.58 (1.13-11.33)*

$1.18(0.77-1.80)$

\subsection{0}

$0.20(0.09-0.42)^{* *}$

CI: Confidence interval, AOR: adjusted odds ratio, 1: Reference category,

$*: 0.001<\mathrm{p}<0.05, * *: \mathrm{p} 0.001$

\section{Figures}




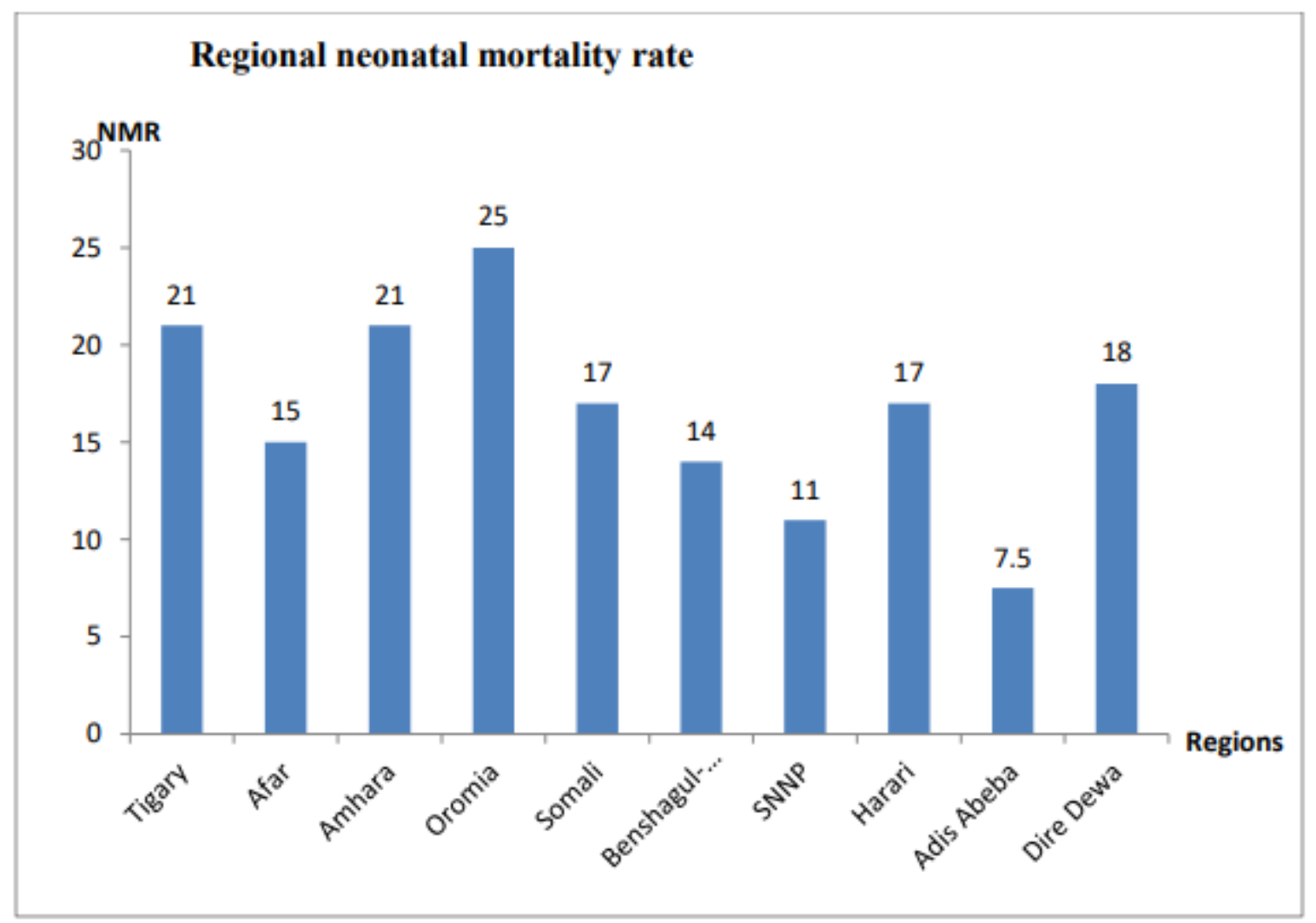

Figure 1

Regional neonatal mortality rate in Ethiopia, 2016 
Moran's Index: 0.1903

z-score: 6.386

p-value: $<0.001$

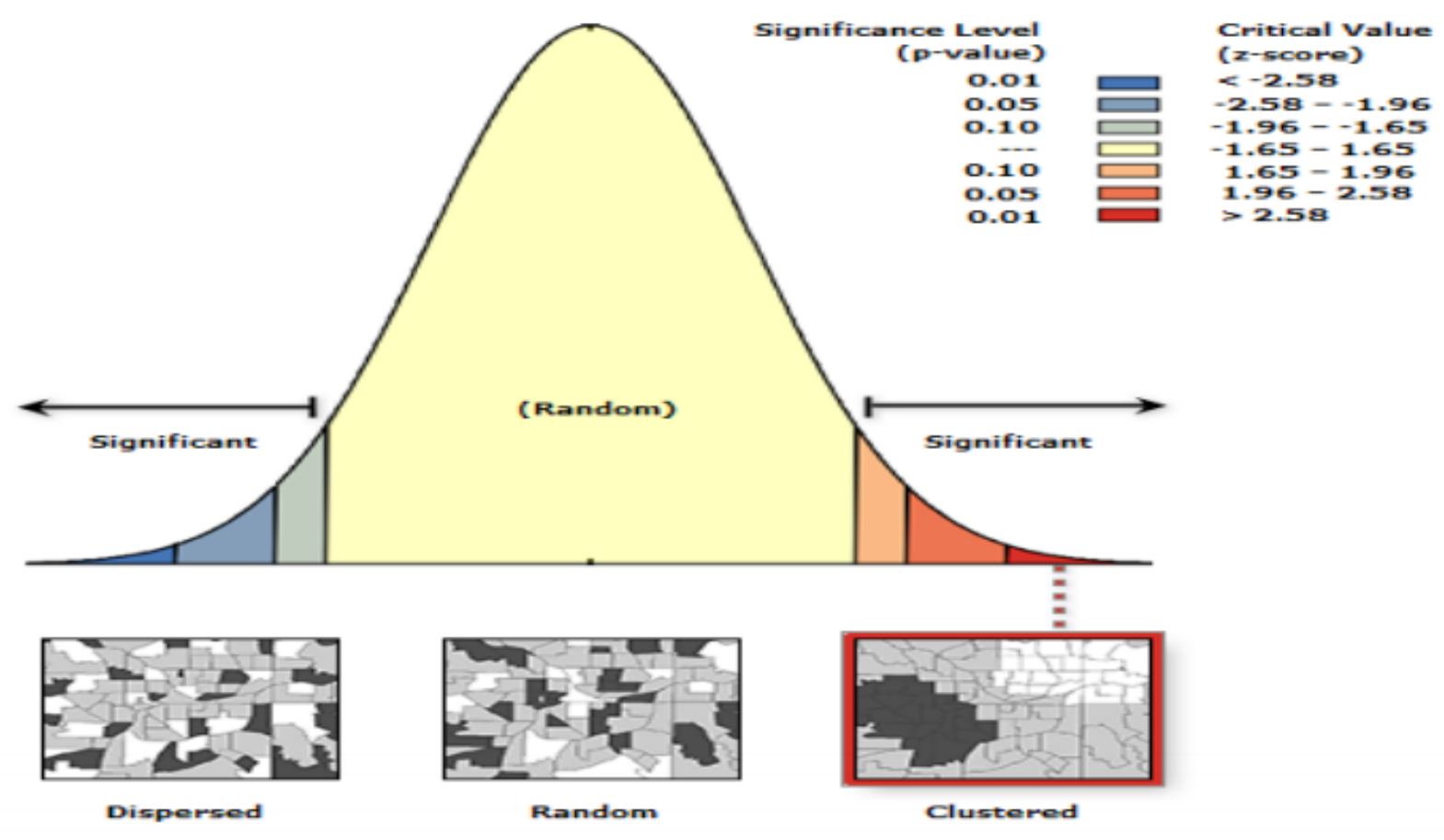

Figure 2

Spatial autocorrelation for distribution of neonatal mortality in Ethiopia, 2016 
Hot spot analaysis of Neonatal Mortality across regions in Ethiopia,2016

$N$
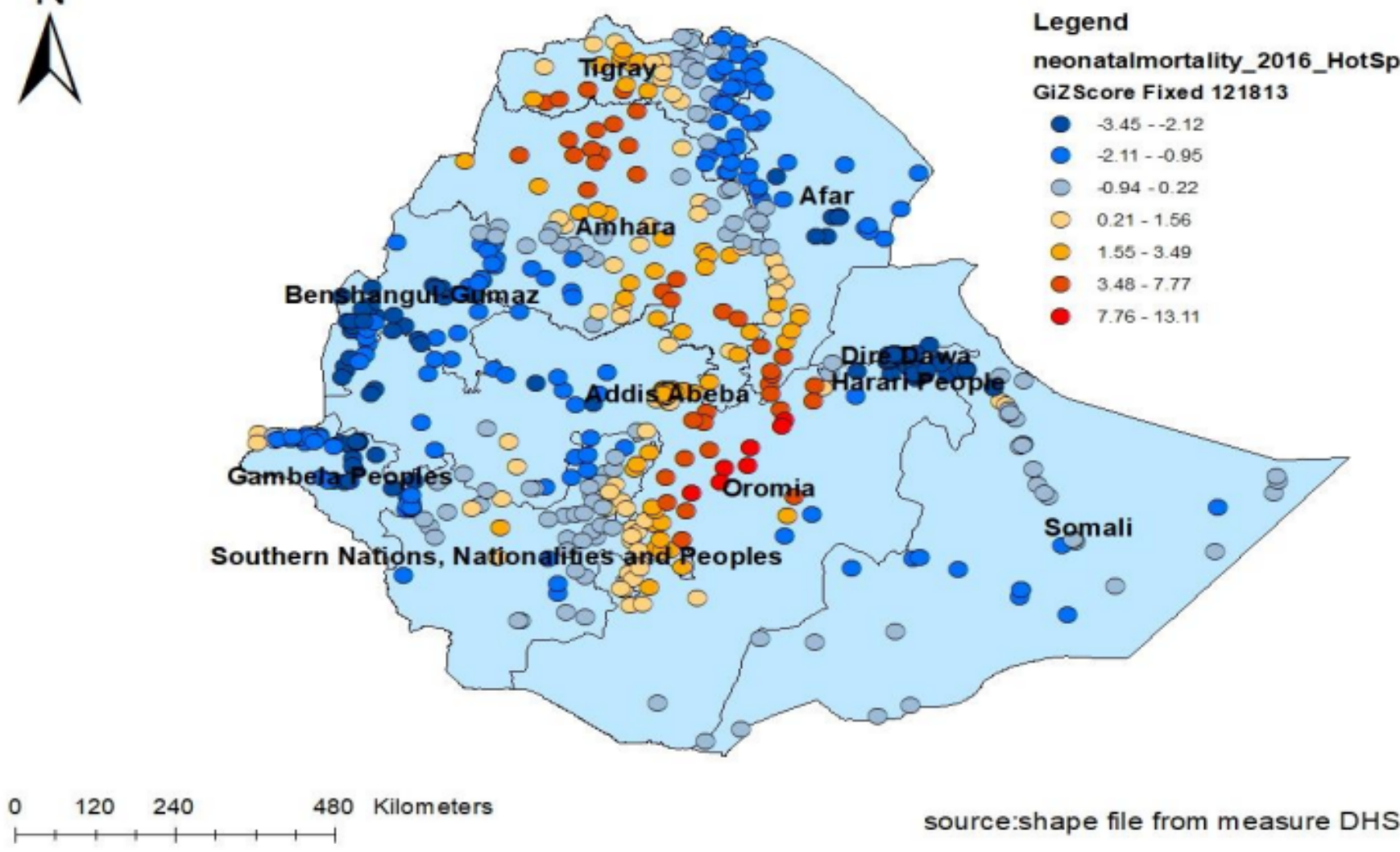

source:shape file from measure DHS

Figure 3

Hot spot and cold spot areas of neonatal mortality in Ethiopia, 2016 

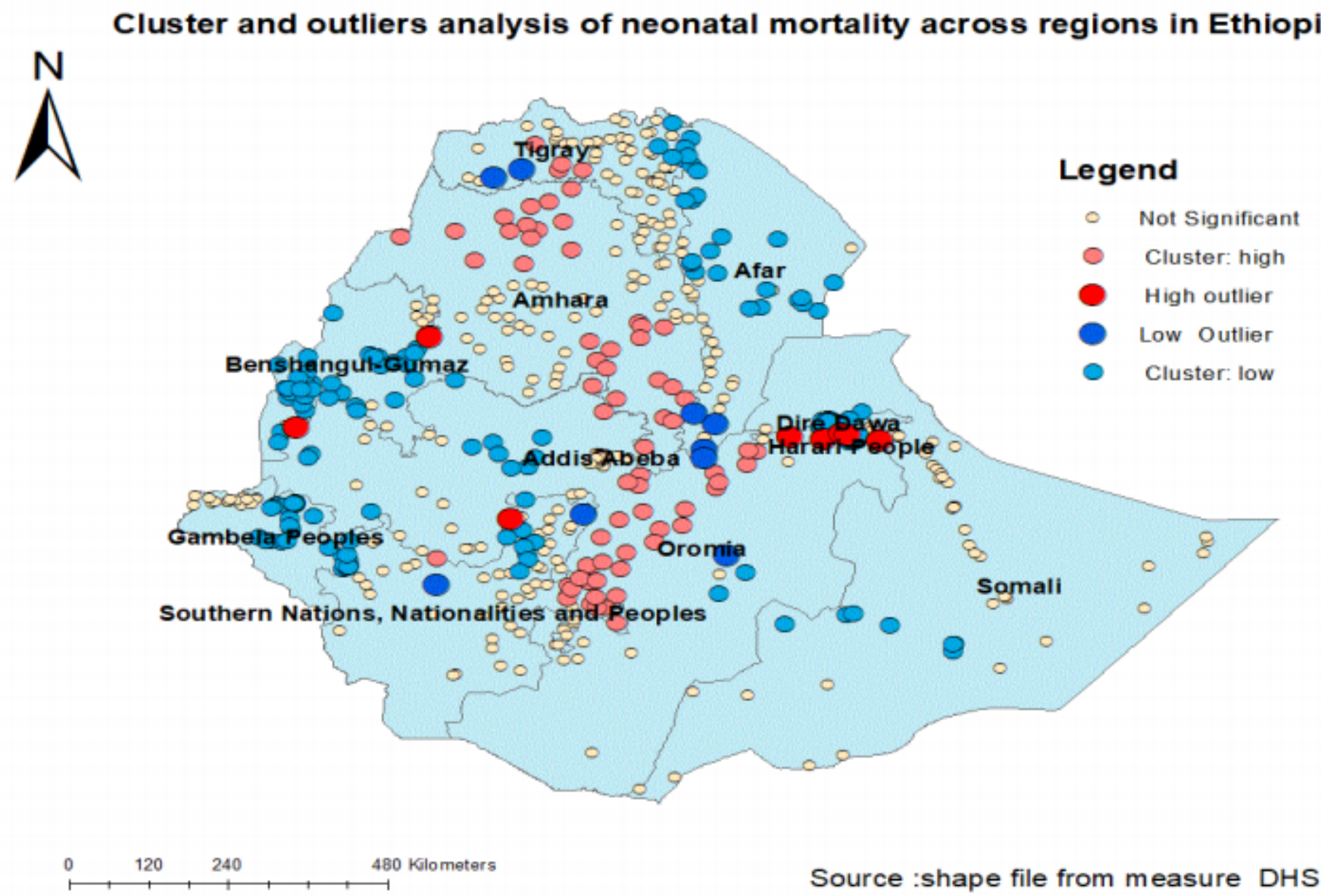

Source :shape file from measure DHS

Figure 4

clusters and outlier identification of neonatal mortality in Ethiopia, 2016 


\section{Spatial interpolation of Neonatal Mortality across regions in Ethiopia,2016}

$N$

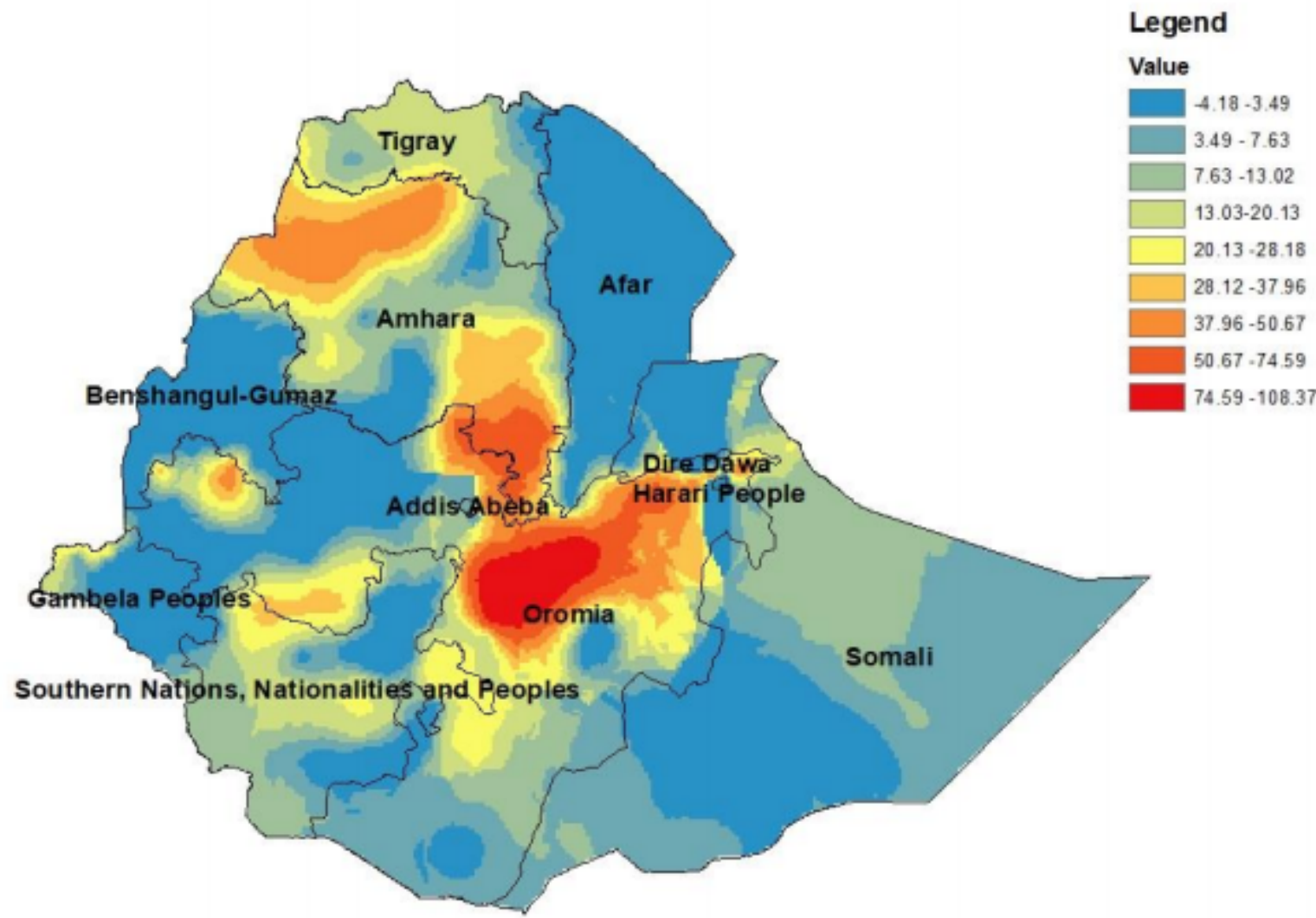

$\begin{array}{llll}0 & 120 & 240 \quad 480 & \text { Kilometers }\end{array}$

source:shape file from measure DHS

Figure 5

Spatial interpolation of neonatal mortality across regions in Ethiopia, 2016 


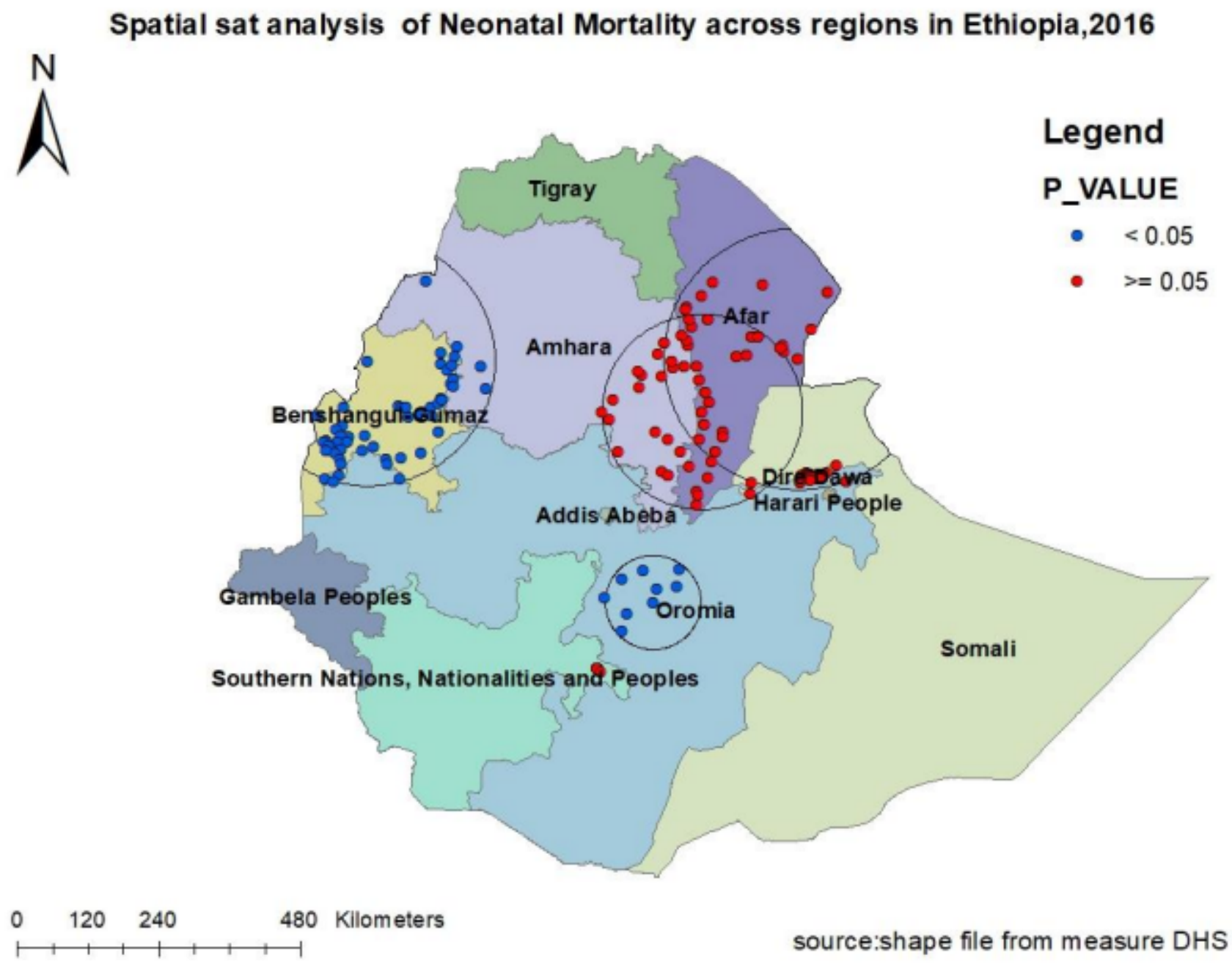

Figure 6

The primary and secondary clusters of neonatal mortality in Ethiopia, 2016 